\section{A pressure-sensitive mechanism to detect the movement of small birds}

\author{
T. HORVATH* \\ University of Windsor \\ Windsor 11, Ontario, Canada N9B $3 P 4$
}

Many experimental designs call for the detection of an animal's presence in various parts of an apparatus or in proximity to some target stimulus. For most purposes, pressure-sensitive floor panels that trigger recorders when depressed by S's weight represent a convenient solution. The apparatus described here was designed to measure preference between pairs of stimuli in the house sparrow, Passer domesticus, and represents a variation on this theme. Research of this nature frequently entails data collection over extended periods; thus, the apparatus was designed to provide adequate living accommodations and, insofar as possible, to be relatively free from disruption in its operation by accumulated fecal droppings. Since intended for use with birds, flat surface or hardware cloth floors were rejected in favor of perch grids. The most troublesome aspect of design stemmed from the fact that the house sparrow is a light animal (approximately $26 \mathrm{~g}$ ) and is able to step on and off a perch very lightly; thus. a high degree of sensitivity was required. Numerous systems involving counterbalanced perches, microswitches, mercury switches, and photoelectric beams were tested, but all proved unsuitable because of inadequate sensitivity. unreliability over extended use, or expense. The system finally devised relies on bare contacts.

The apparatus hull is constructed of galvanized sheet metal and consists of three chambers; two of these are stimulus viewing chambers, each measuring $18 \times 25 \mathrm{~cm}$ and connected by passageway to a living chamber measuring $25 \times 25 \mathrm{~cm}$. The viewing chambers have pressure-sensitive perch grid floors for the detection of $S$ 's presence in them and a $7 \times 10 \mathrm{~cm}$ opening cut in the front wall for viewing stimuli through a clear Plexiglas window, mounted so as to be easily removable for cleaning. The living chamber is fitted with an externally mounted food hopper and water bottle (common pet supplies), a roosting perch, and contains a $10 \times 15 \mathrm{~cm}$ door in the back wall for insertion and recovery of Ss. Figure 1 represents an overhead view showing configuration and dimensions in centimeters. Door screening and $12-\mathrm{mm}$ mesh hardware cloth serve as ceiling and floor material, respectively, and are attached with bolts to top and bottom flanges running the perimeter of the hull (not shown in Fig. 1). The floor to ceiling height is $20 \mathrm{~cm}$. At some points $7.5-\mathrm{cm}$ bolts are used to attach the hardware cloth floor to the bottom flanges, such that these act as legs upon which the

*The author wishes to thank W. Somes, departmental technologist. for his assistance in the design and construction of this apparatus. apparatus stands, thus allowing bedding material to be slid underneath.

Assembly of the pressure-sensitive perch grids is as follows: A 3 -mm-diam stainless steel rod suspended centrally between the viewing chambers $2.5 \mathrm{~cm}$ above floor level serves as a hinge for 6.mm-diam hardwood dowel rods that form the perch grids. Each of these perch dowels is drilied and suspended from the hinge rod and extends under the inside wall of the viewing chamber, ending just short of the outside wall. The bottom edge of the inside walls is $3.5 \mathrm{~cm}$ above floor level. At the free extremity, each perch dowel is drilled lengthwise with a centered hole to accept a $3-\mathrm{mm}$ stainless rod to a depth of $3 \mathrm{~cm}$. A row of $10-\mathrm{mm}$ holes, centered $2.5 \mathrm{~cm}$ above floor level and $2 \mathrm{~cm}$ apart, is drilled through the outside wall of each viewing chamber. Washers are used to space the perch dowels approximately $2 \mathrm{~cm}$ apart on the hinge rod; then each is fitted with a $5.5-\mathrm{cm}$ length of stainless rod in the lengthwise hole at the free end. These short rods, thus, protrude $2.5 \mathrm{~cm}$ from the end of each perch dowel, through a $10-\mathrm{mm}$ hole, and approximately $2 \mathrm{~cm}$ beyond the outside wall of the viewing chamber (see Fig. 1).

Mounted on the exterior of the viewing chamber outside walls is a 6-mm-thick Plexiglas plate, with vertical guide slots just wide enough to allow free movement of the protruding rods. A $3 \mathrm{~mm}$ stainless rod is mounted horizontally so as to limit the downward travel of the protruding rods. Centered above each guide slot is a hole tapped to accept a 6/32 machine screw. The apparatus is wired (Fig. 2) by connecting the protruding rod from each perch dowel to its overhead machine screw, adding interconnections, and finally taking one lead to the recorder. The second lead is taken from the horizontal stainless rod. In this configuration, the recorder responds while any perch dowel is depressed and its protruding rod remains in contact with the horizontal rod. Each perch dowel is individually suspended $2-3 \mathrm{~mm}$ above the horizontal rod by means of

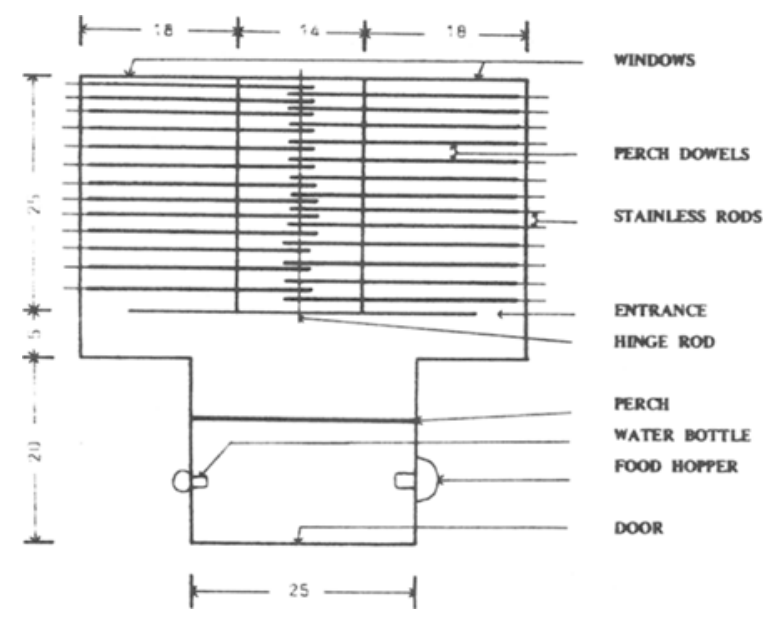

Fig. 1. Overhead drawing showing dimensions in centimeters. 


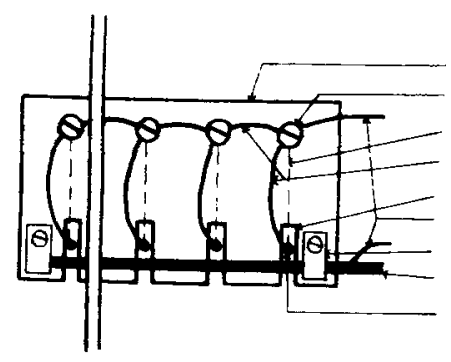

PLEXIGLAS PLATE

MACHINE SCREW

ELASTIC THREAD

MRE CONNECTIONS

GUIDE SLOT

RECORDER LEADS

MOUNTING CLP

HORIZONTAL STAINLESS ROD

PROTRUDING STAINLESS ROD

Fig. 2. Exterior assembly and wiring schematic.

nylon elastic thread, available in any sewing shop (see Fig. 2). The use of elastic thread is the key to the apparatus' sensitivity, as variations in thread tension can produce virtually any degree of sensitivity desired. The apparatus functions very well when each perch dowel can be depressed by half of the S's weight applied at the inside wall of the viewing chamber. The elastic thread seems practically immune to fatigue effects; sensitivity is maintained for long periods without any necessity for resetting. The apparatus has proven remarkably reliable and trouble-free.

Since the individual perch dowels are isolated sensors, this apparatus has a potential for data collection beyond the detection of S's presence in the viewing chambers. By connecting subsets of the perch dowels to different recorder pens, e.g., front and rear halves, or, in the extreme case, by connecting each to a separate pen, Es could obtain information regarding tendencies to approach or retreat from the stimuli, in addition to activity patterns in the viewing chambers. Discrete trial testing can be done by inserting guillotine doors through the ceiling to block off viewing chamber entrances. The ceiling screen permits direct viewing into the chambers. House sparrows, at least, are extremely sensitive to an E's presence in the laboratory, so a suitable arrangement of mirrors or a perch-activated ciné-camera may be needed.

(Received for publication May 17, 1973; revision received October $5,1973$. 